\title{
The Impact of Stratospheric Circulation Extremes on Minimum Arctic Sea Ice Extent $\mathscr{O}$
}

\author{
KAREN L. SMITH ${ }^{\mathrm{a}}$ \\ Lamont-Doherty Earth Observatory, Palisades, New York \\ LORENZO M. POLVANI \\ Department of Applied Physics and Applied Mathematics, and Department of Earth and Environmental Sciences, \\ Columbia University, New York, New York \\ L. BRUNO TREMBLAY \\ Department of Atmospheric and Oceanic Sciences, McGill University, Montreal, Quebec, Canada
}

(Manuscript received 24 July 2017, in final form 17 April 2018)

\begin{abstract}
Given the rapidly changing Arctic climate, there is an urgent need for improved seasonal predictions of Arctic sea ice. Yet, Arctic sea ice prediction is inherently complex. Among other factors, wintertime atmospheric circulation has been shown to be predictive of summertime Arctic sea ice extent. Specifically, many studies have shown that the interannual variability of summertime Arctic sea ice extent (SIE) is anticorrelated with the leading mode of extratropical atmospheric variability, the Arctic Oscillation (AO), in the preceding winter. Given this relationship, the potential predictive role of stratospheric circulation extremes and stratosphere-troposphere coupling in linking the AO and Arctic SIE variability is examined. It is shown that extremes in the stratospheric circulation during the winter season, namely, stratospheric sudden warming (SSW) and strong polar vortex (SPV) events, are associated with significant anomalies in sea ice concentration in the Barents Sea in spring and along the Eurasian coastline in summer in both observations and a fully coupled, stratosphere-resolving general circulation model. Consistent with previous work on the AO, it is shown that SSWs, which are followed by the negative phase of the AO at the surface, result in sea ice growth, whereas SPVs, which are followed by the positive phase of the $\mathrm{AO}$ at the surface, result in sea ice loss, although the mechanisms in the Barents Sea and along the Eurasian coastline are different. The analysis suggests that the presence or absence of stratospheric circulation extremes in winter may play a nontrivial role in determining total September Arctic SIE when combined with other factors.
\end{abstract}

\section{Introduction}

Since 2007, a year of, what was at the time, unprecedented Arctic sea ice loss, there has been a substantial and organized effort to improve seasonal Arctic sea ice prediction in order to better inform industries and communities that depend on reliable sea ice information (Stroeve et al. 2015; Jung et al. 2016). To that

Supplemental information related to this paper is available at the Journals Online website: https://doi.org/10.1175/JCLI-D-17-0495.s1.

\footnotetext{
${ }^{\text {a }}$ Current affiliation: Department of Physical and Environmental Sciences, University of Toronto Scarborough, Toronto, Ontario, Canada.

Corresponding author: Karen L. Smith, karen.smith@utoronto.ca
}

end, recent studies have focused on identifying key sources of Arctic sea ice predictability to improve both statistical and dynamical sea ice forecasts (Petty et al. 2017; Bushuk et al. 2017; Chen et al. 2017; Schröder et al. 2014; Stroeve et al. 2014b; Tietsche et al. 2013).

Among other factors, tropospheric circulation anomalies have been shown to be predictive of interannual variability in Arctic sea ice (Rigor et al. 2002; Ogi et al. 2010). Specifically, studies have demonstrated an anticorrelation between the leading modes of extratropical atmospheric variability, the Arctic Oscillation (AO) and the North Atlantic Oscillation (NAO), in winter and spring and Arctic sea ice extent in summer (Rigor et al. 2002; Rigor and Wallace 2004; Strong et al. 2009; Ogi et al. 2010; Wu and Zhang 2010; Stroeve et al. 2011; Wettstein and Deser 2014; Williams et al. 2016). In the presence of rapid Arctic sea ice decline, the relationship 
between the $\mathrm{AO}$ and sea ice extent is complex (Holland and Stroeve 2011; Ogi et al. 2010), yet recent work demonstrates the increasing predictive skill of wintertime atmospheric circulation on the September Arctic sea ice minimum (Kimura et al. 2013; Williams et al. 2016; Itkin and Krumpen 2017). Williams et al. (2016) emphasizes that the dramatic loss of thick, multiyear ice has led to enhanced atmosphere-sea ice coupling. When this is taken into account, one finds a significant anticorrelation between the late winter AO and September Arctic sea ice extent (SIE; Williams et al. 2016). The anticorrelation is due, in part, to increased sea ice divergence along the East Siberian Sea and Laptev Sea coastlines when the AO is in its positive phase. This increased divergence along the Eurasian coastline promotes growth of thin, first-year ice that melts more readily throughout the summer months, leading to an earlier retreat that is amplified by the ice-albedo feedback and resulting in anomalously low September Arctic SIE (Stroeve et al. 2012; Itkin and Krumpen 2017).

Given this relationship between Arctic SIE and the $\mathrm{AO} / \mathrm{NAO}$ and the need for better seasonal predictions of Arctic SIE (Stroeve et al. 2015; Jung et al. 2016), our aim is to extend previous work to examine whether wintertime stratospheric circulation plays a role in Arctic sea ice variability. Interannual anomalies in the Arctic stratospheric circulation migrate downward to the troposphere, projecting strongly onto the $\mathrm{AO}$ and NAO. Notably, it is well established that stratospheric sudden warmings (SSWs), abrupt reversals of the wintertime stratospheric polar vortex, precede negative phases of the AO/NAO. Thus, SSWs could potentially lead positive anomalies in Arctic SIE and, vice versa, the absence of SSWs may be associated with negative anomalies in SIE. These stratosphere-tropospherecoupled AO/NAO anomalies tend to persist for $\sim 40$ 60 days (Baldwin and Dunkerton 2001; Charlton-Perez et al. 2013), leading to enhanced predictability in the troposphere in winter and early spring following large stratospheric circulation anomalies (Baldwin and Dunkerton 2001; Sigmond et al. 2013; Scaife et al. 2016). This persistence may result in a relatively strong influence of the stratospheric circulation on Arctic sea ice via the $\mathrm{AO} / \mathrm{NAO}$.

On longer time scales, the observed, accelerated loss of Arctic sea ice concentration in the 1990s has been associated with the positive trend in the AO (Rigor et al. 2002). This positive trend in the AO has itself been linked to the lack of SSWs and weakened stratospheretroposphere coupling during that decade (Scaife et al. 2005; Douville 2009), suggesting a potential connection between the stratospheric circulation and Arctic sea ice. As seasonal forecasts of Arctic sea ice become increasingly important in a warming climate, wintertime stratospheric information may help increase the predictive skill and lead times for these forecasts (Sigmond et al. 2013; Scaife et al. 2016).

In this paper, we show that extremes in the stratospheric circulation during the winter season are followed by significant anomalies in SIE along the Eurasian coastline in summer in both observations and fully coupled, stratosphere-resolving general circulation model integrations (GCM). Our goal here is to present evidence for a potential stratospheric source of Arctic sea ice predictability and further work is required to quantify the detailed contributions to the dynamical and thermodynamical processes involved.

In section 2, we describe the GCM and observational data used and define stratospheric circulation extremes, namely, SSW and strong polar vortex (SPV) events. Because the number of SSW and SPV events in the observational record is small we start, in section 3 , by presenting an analysis of a 400-yr-long GCM control integration to establish robust signals and to examine the mechanisms. We then turn to the observations (section 4) and show that they are in good agreement with the GCM results, albeit less statistically robust owing to the shorter record.

\section{Methods}

\section{a. Model and control integration}

We analyze a long, time-slice integration of the Whole Atmosphere Community Climate Model (WACCM), the stratosphere-resolving, coupled-chemistry version of the NCAR Community Earth System Model, version 1 [CESM1(WACCM)]. The atmospheric component of WACCM has 66 vertical levels with a model top at $140 \mathrm{~km}$, a horizontal resolution of $1.9^{\circ} \times 2.5^{\circ}$ specialized parameterizations for gravity waves, and other upperatmospheric processes and fully interactive middle atmosphere chemistry. In the integration examined here, WACCM is coupled to identical interactive land, ocean, and sea ice models as in the simulations conducted as part of phase 5 of the Coupled Model Intercomparison Project (CMIP5), described in Marsh et al. (2013).

It is important to note that WACCM has an annual mean Arctic SIE that is well within the spread of the CMIP5 models for the 1979-2005 time period [13.44 vs the multimodel mean of 12.81 million $\mathrm{km}^{2}$, see Shu et al. (2015)]. However, the climatological WACCM sea ice thickness is biased high relative to observationally based data products (Stroeve et al. 2014a), such as the PanArctic Ice Ocean Assimilation System (PIOMAS; Zhang and Rothrock 2003). In particular, WACCM 
has a relatively high sea ice thickness bias along the Eurasian coastline in winter and spring. (For reference, in the supplementary material Figs. S1, S3, and S5 show the WACCM climatological mean sea ice concentration, thickness, and velocity and Figs. S2 and S4 show the climatological standard deviation of sea ice concentration and thickness.)

The WACCM integration used in this study is a 400-yr-long, time-slice integration, with all forcings, including $\mathrm{CO}_{2}$, ozone-depleting substances, aerosols, etc., set at constant year-2000 values. Daily model output is available for all atmospheric fields of interest (zonal wind, sea level pressure, surface wind stress), as well as for sea ice concentration. All other sea ice fields, such as thickness, ice velocities and concentration and volume tendencies, are available at monthly resolution.

\section{b. Observational data}

As discussed in the introduction, our study was initially motivated by observational analysis, which we discuss at the end of the paper (section 4). For that analysis, we use ERA-Interim reanalysis data from 1979 to 2015 (Dee et al. 2011) to identify anomalies in the stratospheric circulation and we use the daily National Snow and Ice Data Center (NSIDC) bootstrap sea ice concentration (SIC) data from 1979 to 2015 (Comiso 2000, updated 2015). We linearly interpolate the everyother-daily NSIDC SIC data from 31 December 1978 to 31 July 1987 to daily resolution, and combine these with the daily data from 1 August 1987 to 31 December 2015. Missing data between 3 December 1987 and 12 January 1988 are replaced with a daily climatology representative of the early part of the Arctic sea ice record, the 1979-1992 daily average. Within the polar data gap, a region over the pole where satellite coverage is incomplete [the NSIDC SIC data contain a circular data mask centered on the pole with a radius ranging from $611 \mathrm{~km}$ in $1979,311 \mathrm{~km}$ in 1988 , and $94 \mathrm{~km}$ at present, Strong and Golden (2016)], we replace missing data with $100 \%$ SIC. The SIC data were then regridded from the $\mathrm{SSM} / \mathrm{I}$ polar-stereographic grid to the WACCM $1^{\circ} \times 1^{\circ}$ latitude-longitude sea ice grid using the NSIDC geocoordinate tools. We detrend the SIC data using a quadratic fit; however, our composite analysis is qualitatively insensitive to whether we linearly or quadratically detrend the SIC data.

\section{c. SSW and SPV identification and composite analysis}

We examine the relationship between anomalies in the stratospheric circulation and Arctic sea ice by performing composite analysis of extremes in polar stratospheric zonal mean zonal wind, namely, SSWs and SPVs. The climatological wintertime stratospheric polar vortex is characterized by strong westerly winds. SSWs are abrupt transitions of this westerly wind to easterly conditions. SSWs are identified when the daily zonal mean zonal wind at $60^{\circ} \mathrm{N}$ and $10 \mathrm{hPa}$ becomes easterly (the first day that satisfies this criterion is called the "central date"). Individual SSW events within the same winter season must be separated by at least 20 days of westerlies and we exclude all final warmings (Charlton and Polvani 2007). Using the above definition, the frequency of SSWs in global reanalysis products is approximately five events per decade (Butler et al. 2015). SPVs are identified in a similar way, when the daily zonal mean zonal wind at $60^{\circ} \mathrm{N}$ and $10 \mathrm{hPa}$ exceeds a threshold of $48 \mathrm{~m} \mathrm{~s}^{-1}$ (Scaife et al. 2016). This threshold is somewhat arbitrary, but yields a similar number of SPVs as SSWs in both the WACCM simulation and the reanalysis. As for SSWs, we require that individual SPVs within the same winter season be separated by at least 20 days of winds that are weaker than the threshold.

We perform two composite analyses. The first is based on the central date of the SSW or SPV. This method of composite analysis requires daily model output. The second is based on seasonal averages for years with SSWs or SPVs using monthly model output. For both methods, we have excluded years in which both a SSW and a SPV occur in the same year. For our 400-yr-long control simulation, using the first method, we initially have 193 SSWs (composite mean central date of 26 January, and standard deviation of 38 days) and 156 SPVs (composite mean central date of 16 January, and standard deviation of 29 days). When we remove overlapping years (years in which we have both a SSW and a SPV) and account for the fact that some years have more than one SSW or SPV, we end up with 126 winters with SSWs and 99 winters with SPVs.

As for the reanalysis, using the first method initially yields 21 SSWs (composite mean central date of 26 January) and 26 SPVs (composite mean central date of 23 December) for 1979-2015 (see supplementary Table S1). If we remove overlapping years, we end up with 8 winters with SSWs and 14 winters with SPVs.

\section{Modeling evidence of a stratospheric impact on Arctic sea ice}

\section{a. Signatures of stratospheric circulation extremes}

Before examining the relationship between extremes in the stratospheric circulation and Arctic sea ice, it is important to first examine the characteristics of SSWs and SPVs in WACCM and demonstrate that they are in good agreement with ERA-Interim reanalysis, and then to show that the surface signatures of SSWs and SPVS 

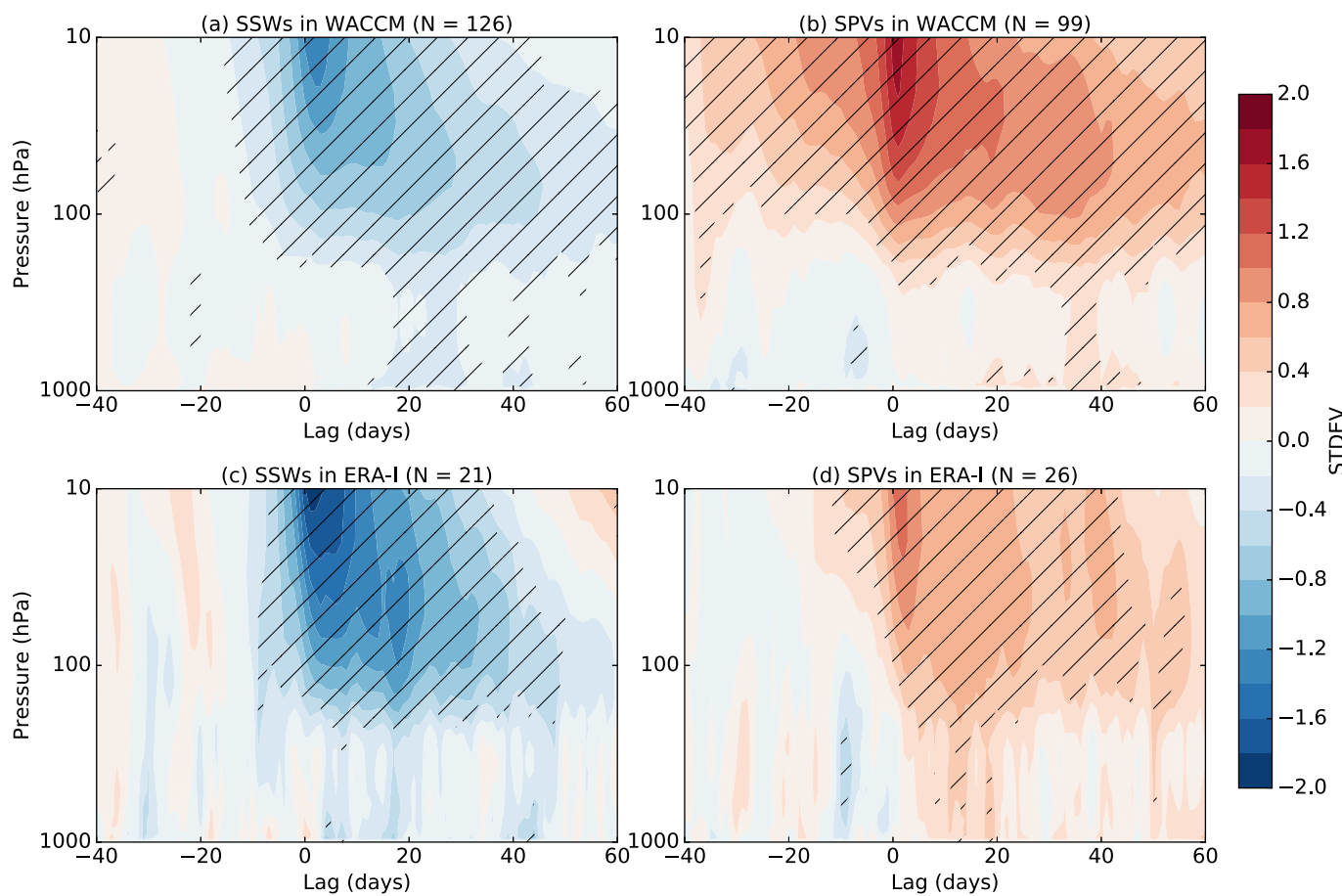

FIG. 1. Composite and zonal mean zonal wind at $60^{\circ} \mathrm{N}$ normalized by its standard deviation $\left(\hat{U} 60^{\circ} \mathrm{N}\right.$; color shading) as a function of lag (days) and pressure (hPa) for (a) SSWs and (b) SPVs in WACCM, and (c) SSWs and (d) SPVs in ERA-Interim. Day zero corresponds to the central date of the SSW or SPV event. Therefore, positive lags indicate that the SSW or SPV event is leading. Grid points that are statistically significant at the $95 \%$ level using a Student's $t$ test are hatched. Here, we are showing composite means for ERA-Interim using all events, 21 SSWs and 26 SPVs, but the results are qualitatively similar for the reduced composite sizes where years containing both SSWs and SPVs have been removed.

are robust to the different composite methods described above.

First, Figs. 1a and 1b show the composite mean daily zonal mean zonal wind anomalies normalized by the daily standard deviation at $60^{\circ} \mathrm{N}\left(\hat{U} 60^{\circ} \mathrm{N}\right)$ for SSWs and SPVs as a function of pressure and lag about the central date (day zero is the central date of the SSW or SPV event). We use normalized zonal mean zonal wind anomalies to more clearly bring out the anomalies in the troposphere. We find that the SSW and SPV definitions clearly reveal extremes in the stratospheric circulation that migrate down to the troposphere and that compare well with reanalysis (Figs. 1c and 1d).

Second, we examine the surface climate anomalies following extremes in the stratospheric circulation. Figures $2 \mathrm{a}$ and $2 \mathrm{~b}$ show the composite mean sea level pressure (SLP) and surface wind stress $(\tau)$ anomalies in WACCM averaged over days 0-40 following the central dates of the SSWs and SPVs, respectively. We find that the pattern of SLP and $\tau$ anomalies closely resemble the negative (Fig. 2a) and positive (Fig. 2b) phases of the AO, and, in the Atlantic region, the NAO. The surface signatures of these extremes are not entirely antisymmetric, with stronger stratosphere-troposphere coupling following SSWs (Baldwin and Dunkerton 2001; Scaife et al. 2016).

Now we compare the above SSW and SPV composites, based on the central dates of the events, to the seasonal composites of winters with SSWs or SPVs [January-February-March (JFM); Figs. 2c and 2d]. Although the tropospheric circulation anomalies based on these seasonal composites are not identical to those based on the central date, we see a qualitative similarity between the two composite methods, suggesting that the presence of a SSW or SPV in a particular winter is the dominant influence on the seasonal mean tropospheric circulation pattern. By extension, using this seasonal composite method to examine sea ice concentration anomalies, we can show the influence of stratospheric circulation extremes in winter on Arctic sea ice. The correspondence between the composite methods also allows us to make use of the monthly model output to examine the relationship between stratospheric circulation extremes and Arctic sea ice in greater detail. Recall, that for sea ice variables, we only have daily model 
(a) SSW Composite: days 0-40

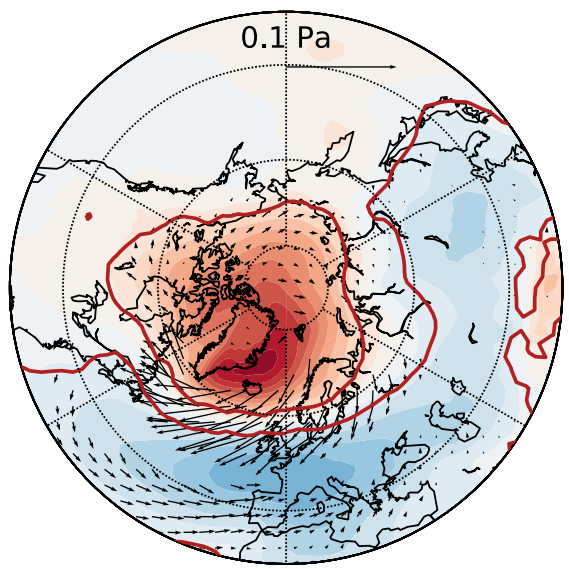

(c) SSW Years: JFM

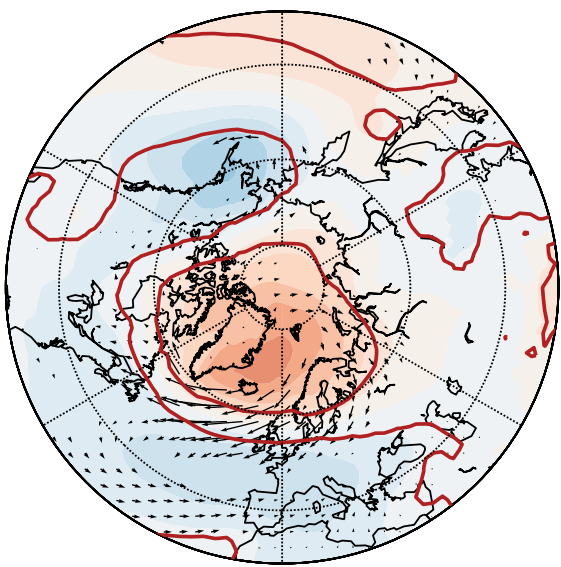

(b) SPV Composite: days 0-40

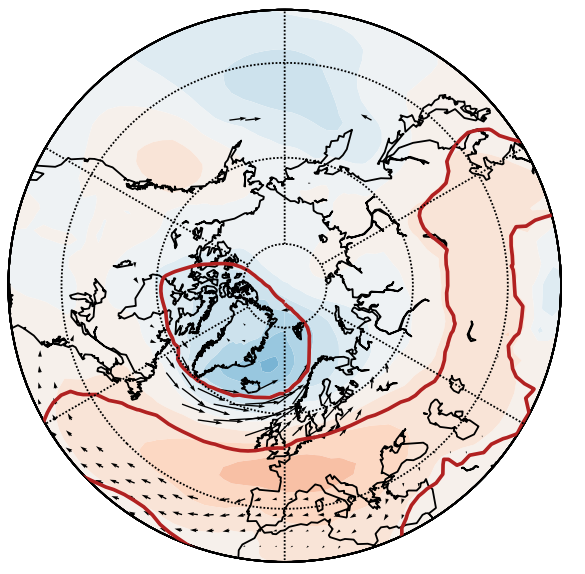

(d) SPV Years: JFM

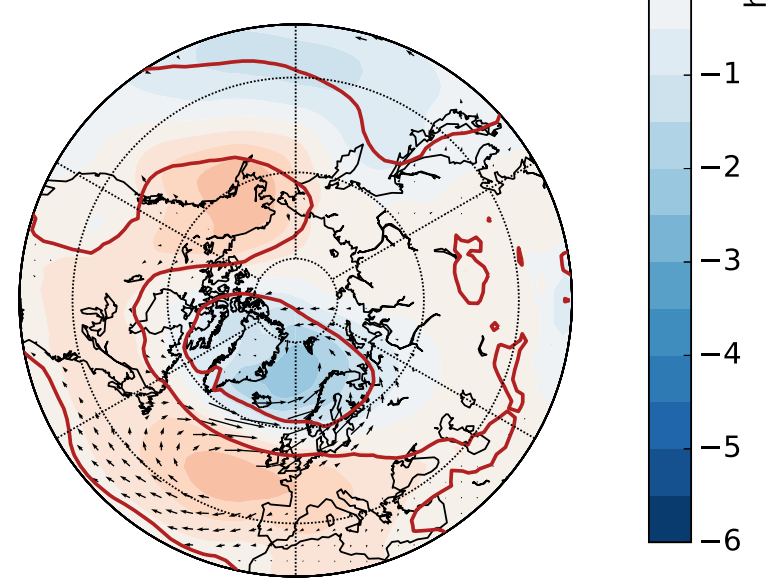

FIG. 2. Composite mean SLP (color shading; units are hPa) and surface wind stress (vectors; units are Pa) anomalies in WACCM for (a) days 0-40 following the SSW central date, (b) days 0-40 following the SPV central date, (c) JFM of years with SSWs, and (d) JFM for years with SPVs. Composites consist of 126 SSWs and 99 SPVs. Grid points of SLP within the red contour are statistically significant at the 95\% level using a Student's $t$ test. Only statistically significant wind stress vectors are displayed.

output for SIC-all other sea ice variables were only output at monthly resolution.

\section{b. Stratospheric influence on Arctic sea ice}

Having established the features of stratospheric circulation extremes in WACCM, and having shown that these features are robust to the compositing methods used, we now turn to anomalies in Arctic sea ice following SSWs and SPVs. Below, we first establish the presence of SIE and SIC anomalies following SSWs and SPVs and then in section $3 \mathrm{c}$, we describe the physical processes in more detail.

First, we examine whether SSWs or SPVs are followed by anomalies in total Arctic SIE. In particular, we are interested in whether SSWs or SPVs are associated with anomalies in the Arctic SIE minimum in the following
September. Figures $3 a$ and $3 b$ show composite mean time series of total SIE as a function of lag for SSWs and SPVs, respectively. We find significant anomalies in total SIE up to $\sim 180$ days following SSWs and SPVs. As expected for the sign of the $\mathrm{AO} / \mathrm{NAO}$, we find that SSWs are associated with positive SIE anomalies, while SPVs are associated with negative SIE anomalies. The SSW and SPV composite mean central dates are 26 and 16 January, respectively, resulting in significant total SIE anomalies stretching into July, but not September. However, the total SIE is not the whole story.

Examination of the SIE anomalies in different regions within the Arctic show that the anomalies in total SIE arise primarily from anomalies in the Barents Sea (BA) and the Bering Strait and Sea of Okhotsk $(\mathrm{B} / \mathrm{O})$ (Figs. 3c,d,g,h). While anomalies in these seas do not 
SSW Composite
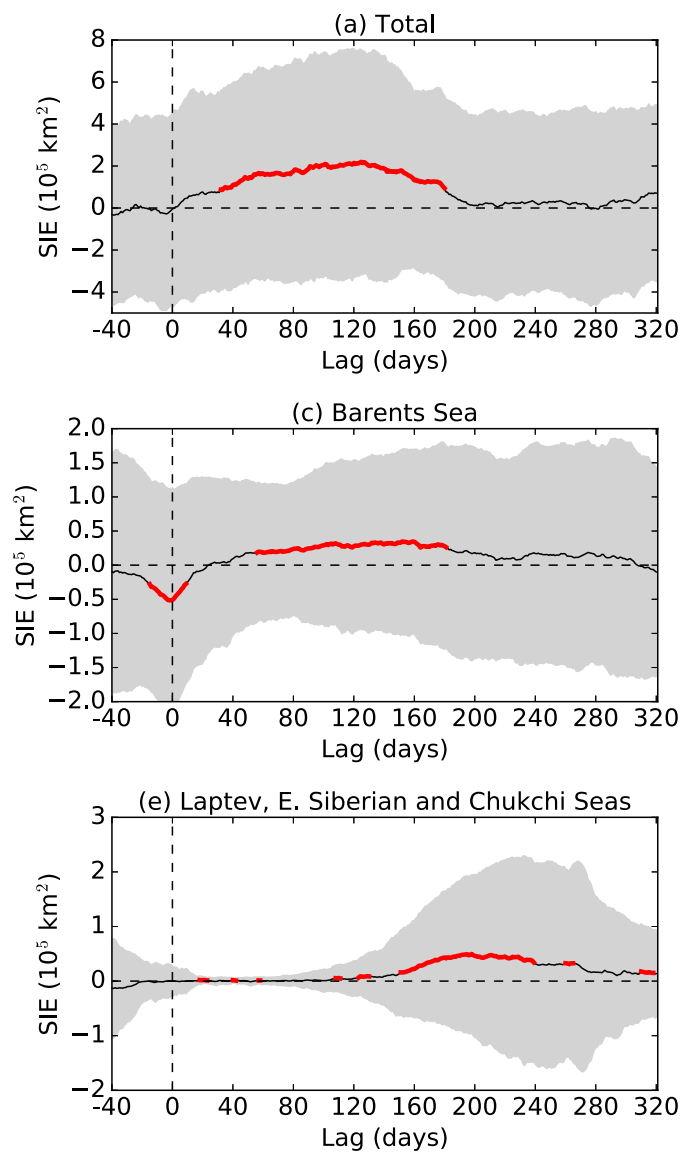

(g) Bering Straight and Sea of Okhotsk

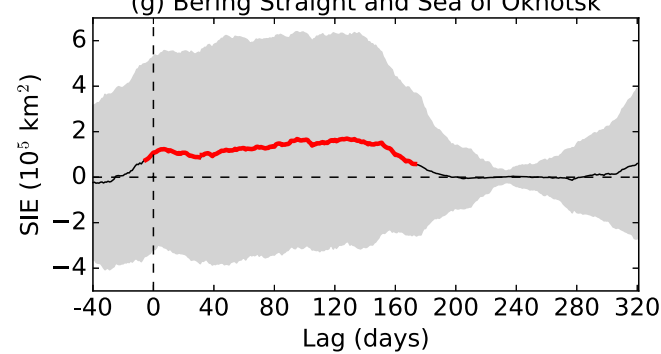

SPV Composite

(b) Total

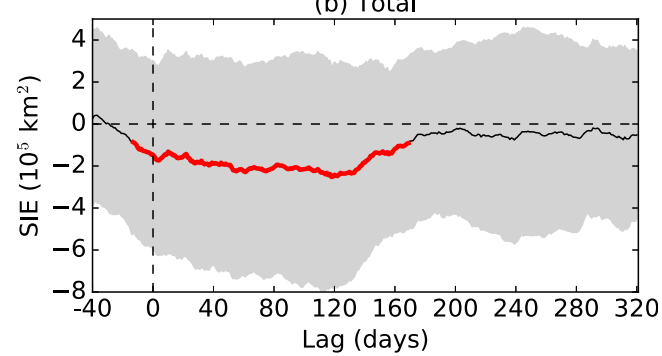

(d) Barents Sea
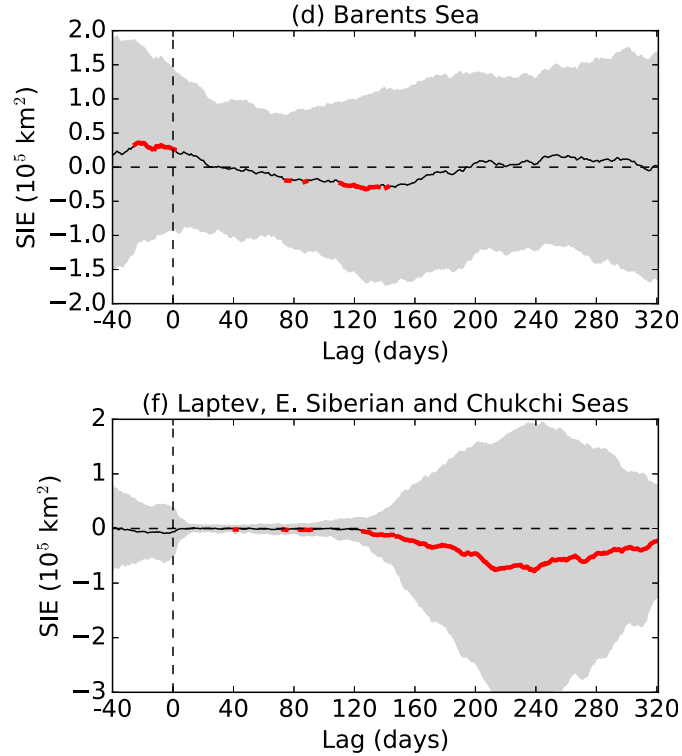

(h) Bering Straight and Sea of Okhotsk

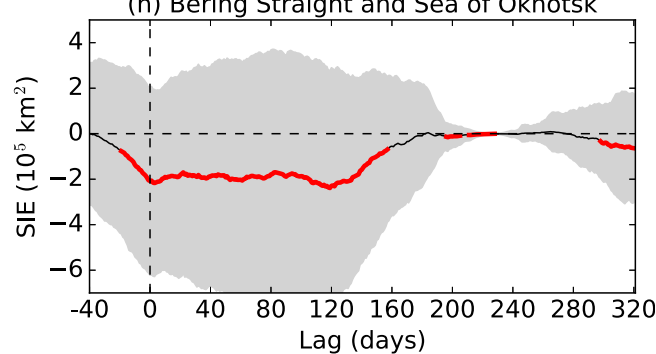

FIG. 3. Composite mean SIE anomaly time series as a function of lag (days) for (left) SSWs and (right) SPVs in WACCM. (a),(b) Total SIE anomalies; (c),(d) Barents Sea $\left(70^{\circ}-80^{\circ} \mathrm{N}, 20^{\circ}-60^{\circ} \mathrm{E}\right)$; (e),(f) Laptev, East Siberian, and Chukchi Seas $\left(65^{\circ}-80^{\circ} \mathrm{N}, 92^{\circ}-200^{\circ} \mathrm{E}\right)$; and $(\mathrm{g})$, (h) Bering Strait $\left(50^{\circ}-65^{\circ} \mathrm{N}, 162^{\circ}-210^{\circ} \mathrm{E}\right)$ and Sea of Okhotsk $\left(45^{\circ}-\right.$ $65^{\circ} \mathrm{N}, 130^{\circ}-162^{\circ} \mathrm{E}$ ). Composites consist of $126 \mathrm{SSWs}$ and 99 SPVs. Days that are statistically significant at the $95 \%$ level using a Student's $t$ test are indicated by the solid red line. Gray shading shows \pm 1 standard deviation across the SSW and SPV events. The black vertical line at day zero indicates the central date of the SSW and SPV events. The regions were chosen based on the temporal and spatial coherence of SIC anomalies (see Fig. 4).

persist into September, we do find significant SIE anomalies in the Laptev, East Siberian, and Chukchi Seas (L/ES/C) following SSWs and SPVs that emerge in summer and persist into autumn (Figs. 3e,f). The reason for focusing only on the above regions in Fig. 3 will become clear below, when we discuss Fig. 4 and the spatiotemporal nature of the SIC anomalies.
The timing of the SIE anomalies shown in Fig. 3 highlights the nature of these anomalies in the different Arctic seas. For example, sea ice in the BA region is relatively thin and, therefore, responds quickly to wind anomalies associated with the $\mathrm{AO} / \mathrm{NAO}$ via anomalous ice advection and ocean heat flux (Bitz et al. 2005; Sorteberg and Kvingedal 2006; Koenigk et al. 2009; 
(a) SSW Years: JFM

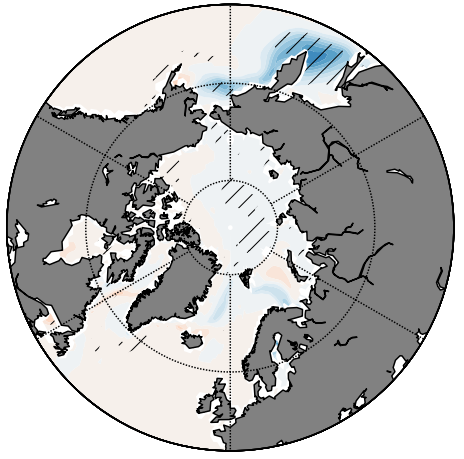

(d) SPV Years: JFM

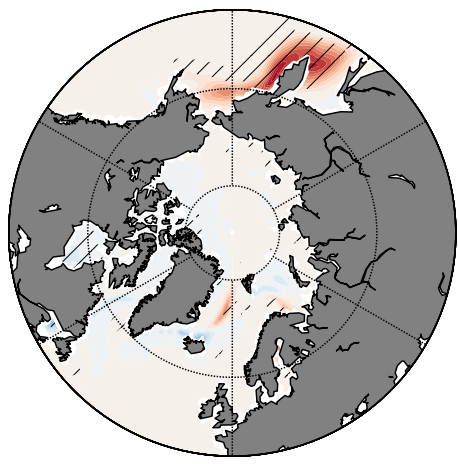

(b) SSW Years: AMJ

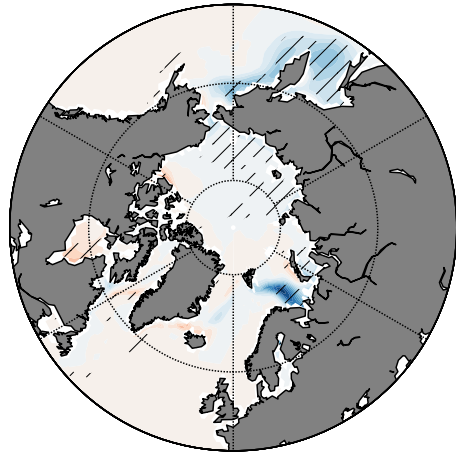

(e) SPV Years: AMJ

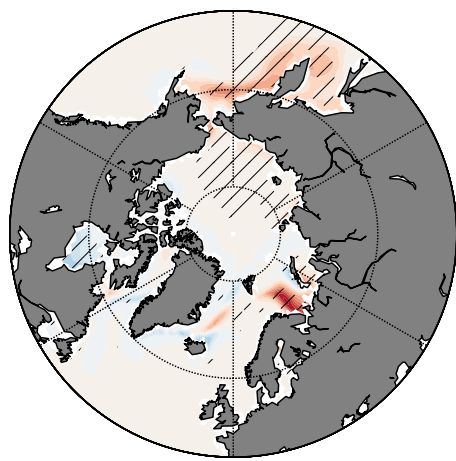

(c) SSW Years: JAS

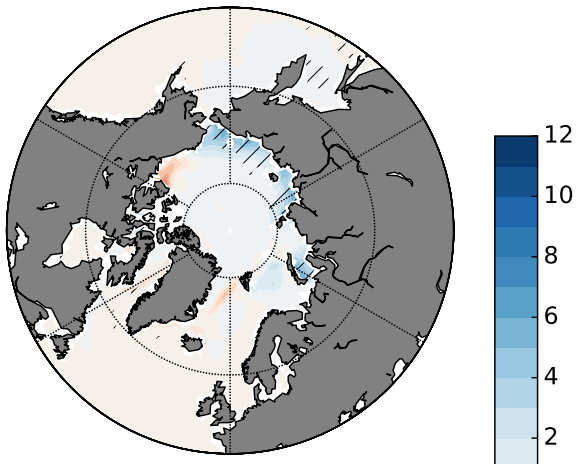

(f) SPV Years: JAS

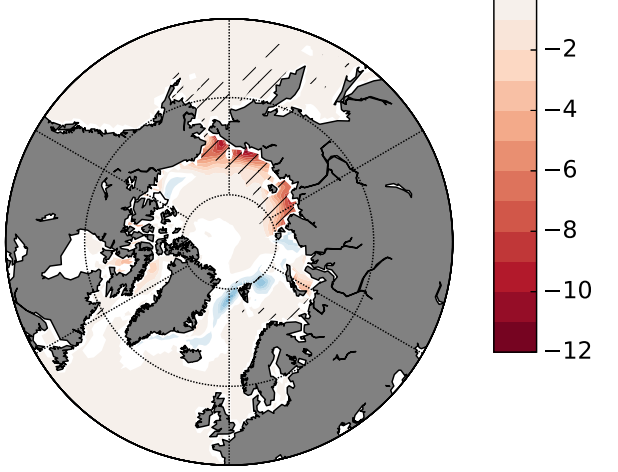

FIG. 4. Composite mean seasonal sea ice concentration anomalies for (a)-(c) years with SSWs and (d)-(f) years with SPVs. Seasonal means are shown for (a),(d) JFM; (b),(e) AMJ; and (c),(f) JAS. Composites consist of 126 SSWs and 99 SPVs. Grid points that are statistically significant at the $95 \%$ level using a Student's $t$ test are hatched.

Strong and Magnusdottir 2010; Arthun et al. 2012), whereas sea ice in the $\mathrm{L} / \mathrm{ES} / \mathrm{C}$ region is thicker and, therefore, has memory of winter conditions that extends well into summer (Williams et al. 2016). We will quantify these processes further in section $3 \mathrm{c}$ below.

We are aware that there has been considerable research interest in the opposite influence, that is, the impact of Arctic sea ice anomalies on the stratospheric circulation (Scinocca et al. 2009; Cai et al. 2012; Sun et al. 2014; Peings and Magnusdottir 2014; Feldstein and Lee 2014; Kim et al. 2014; Sun et al. 2015; Wu and Smith 2016; Yang et al. 2016; Zhang et al. 2018); however, this is not the focus of our study. Here, we are interested in identifying and examining how stratospheric circulation extremes drive SIE anomalies. There is some evidence in Figs. 3c-f that SIE anomalies in the BA and the B/O regions may develop before the SSW and SPV central dates (day zero), and, thus, may, in fact, be sources of anomalous upward wave activity flux driving these events (Yang et al. 2016; Zhang et al. 2018; Garfinkel et al. 2012). In the BA region, the anomalies that coincide with the central date do not persist and, in fact, change sign, suggesting we may potentially treat the anomalies following the central dates independently.
The anomalies preceding the central dates in the $\mathrm{B} / \mathrm{O}$ region persist for months after the central dates, also suggesting that regardless of whether the anomalies existed before the central date, SSWs or SPVs may contribute to the persistence of the $\mathrm{B} / \mathrm{O}$ anomalies.

We also note here that El Niño and La Niña are associated with significant SIC anomalies in the B/O region in WACCM (but, not in the $\mathrm{BA}$ or $\mathrm{L} / \mathrm{ES} / \mathrm{C}$ regions) and that the concurrence of El Niño and La Niña winters with our SSW and SPV winters is not evenly distributed (Polvani et al. 2017). Of our 126 SSW winters, 61 are El Niño years and 47 are La Niña years, while of the 99 SPV winters, 15 are El Niño winters and 11 are La Niña winters. Because it is difficult to disentangle the lead-lag relationships without performing sea ice perturbation experiments (beyond the scope of this paper) and also difficult to quantify the relative importance of ENSO without significantly reducing our composite sizes, we simply focus on the SIE anomalies in the BA region and along the Eurasian coastline following all SSWs and SPVs, irrespective of the ENSO phase.

With these caveats in mind, we now turn to the seasonal composite method and examine the spatial pattern of SIC anomalies in more detail (see supplementary 
(a) SSW Years: JFM

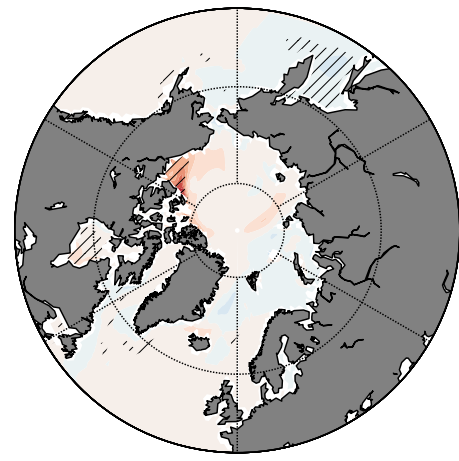

(d) SPV Years: JFM

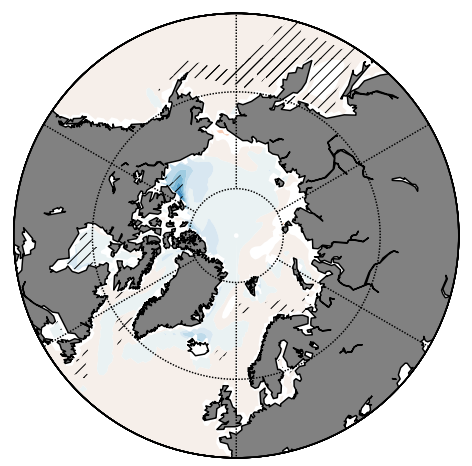

(b) SSW Years: AMJ

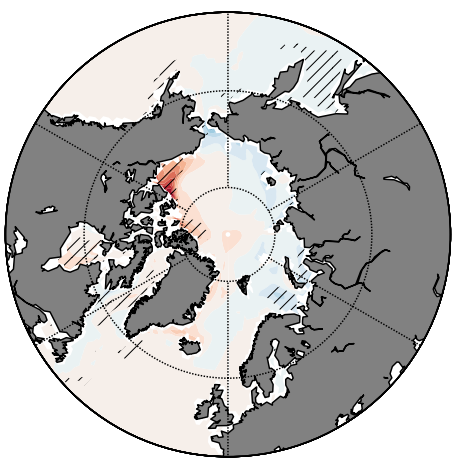

(e) SPV Years: AMJ

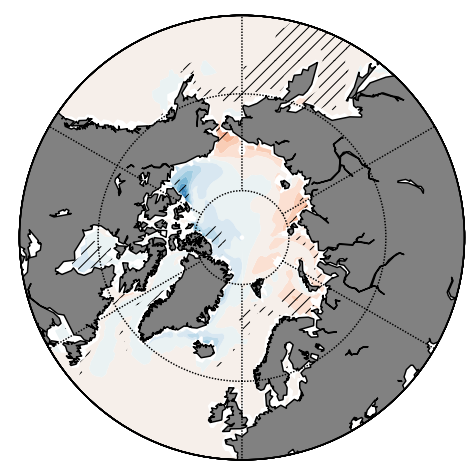

(c) SSW Years: JAS

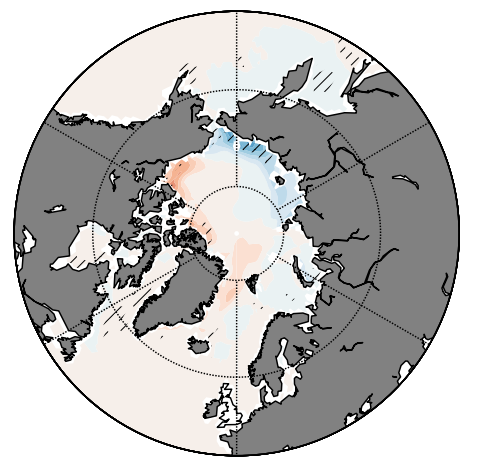

(f) SPV Years: JAS

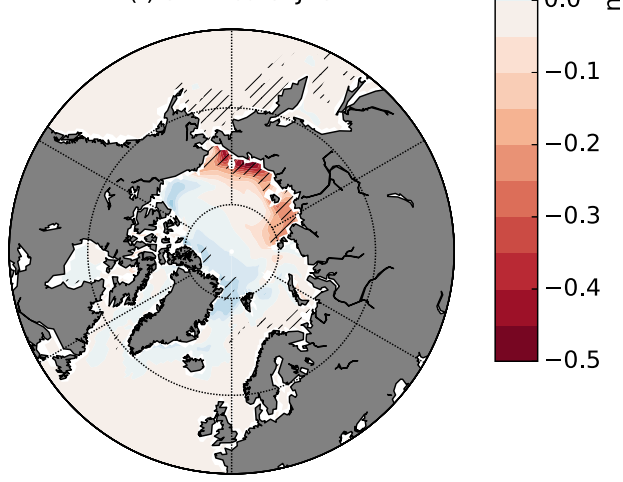

FIG. 5. As Fig. 4, but for sea ice thickness anomalies.

Fig. S6 for similar plots using the central data composite method). The regional SIE anomalies shown in Fig. 3 are clearly visible in Fig. 4. In Figs. 4a and 4d, which show the JFM composite mean SIC anomalies for SSW and SPV years, respectively, we can see the significant anomalies in the $\mathrm{B} / \mathrm{O}$ region (as in Figs. $3 \mathrm{~g}$ and $3 \mathrm{~h}$ ).

In April-May-June (AMJ), we see the full development of SIC anomalies in the BA region (Figs. 4b and $4 \mathrm{e}$ ). These anomalies are quite localized, but relatively large, up to $\sim 12 \%$. Relative to the interannual variability of the entire 400-yr-long WACCM integration, the composite mean anomalies, area averaged over the BA region, represent approximately one-quarter of a standard deviation for both SSWs and SPVs.

Finally, in July-August-September (JAS), we see the emergence of SIC anomalies in the Kara, Laptev, East Siberian, and Chukchi Seas, regions where sea ice concentration in summer is strongly correlated with the $\mathrm{AO} / \mathrm{NAO}$ in winter (Figs. 4c and 4f; Williams et al. 2016). We find positive anomalies following SSWs (Fig. 4c) and negative anomalies following SPVs (Fig. 4f), consistent with the relationship between stratospheric circulation extremes and the AO/NAO. The composite mean anomalies, area averaged over the $\mathrm{L} / \mathrm{ES} / \mathrm{C}$ region, are approximately one-quarter of a standard deviation for SSWs and one-half for SPVs.

\section{c. Processes linking the stratosphere and Arctic sea ice}

Having clearly shown that stratospheric circulation extremes are followed by anomalies in Arctic SIC in WACCM, we now explore the processes giving rise to these anomalies. We identify, in general terms, which factors contribute to the temporal evolution of SIC anomalies in different regions of the Arctic.

We begin by examining anomalies in sea ice thickness. Large anomalies in sea ice thickness collocated with SIC anomalies of the same sign indicate SIC loss or gain via sea ice divergence or convergence within the pack ice, which is known to result in subsequent early or late summer ice retreat (Itkin and Krumpen 2017; Chevallier and Salas-Mélia 2012). In contrast, in regions that are directly connected to the Atlantic and Pacific Oceans, where ice is typically thin, and the ocean is not $100 \%$ ice covered, SIC anomalies tend to be associated with thickness anomalies that are small in magnitude. We will see below that, contributions from both anomalous ice advection and thermodynamic processes, such as atmospheric and ocean heat transport appear to be important in these regions in WACCM (Bitz et al. 2005; Koenigk et al. 2009; Strong and Magnusdottir 2010).

Figures 5a,b and 5d,e show JFM and AMJ composite mean thickness anomalies for SSW and SPV years, 
(a) BA Region: SIC and SIC Tendency



(c) BA Region: Ice Thickness and Volume Tendency

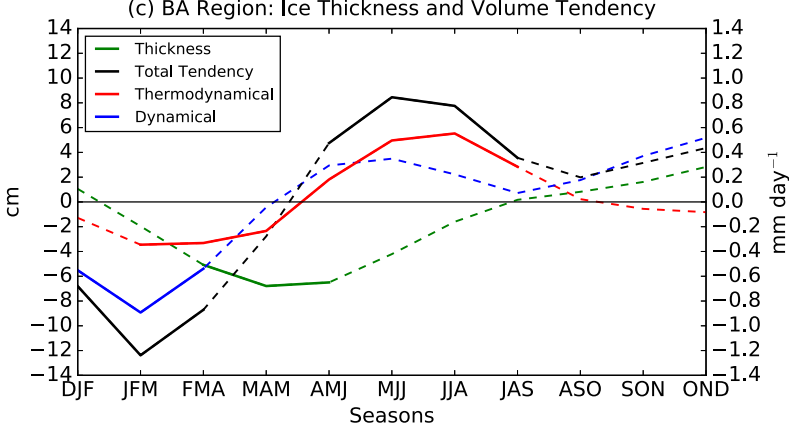

(b) L/ES/C Region: SIC and SIC Tendency

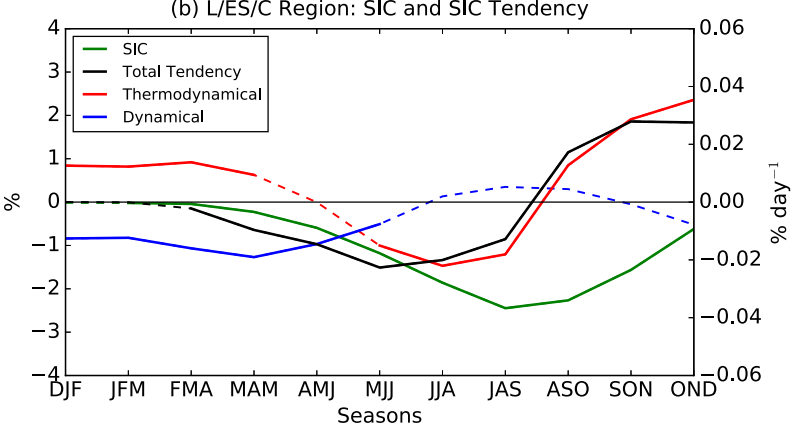

(d) L/ES/C Region: Ice Thickness and Volume Tendency

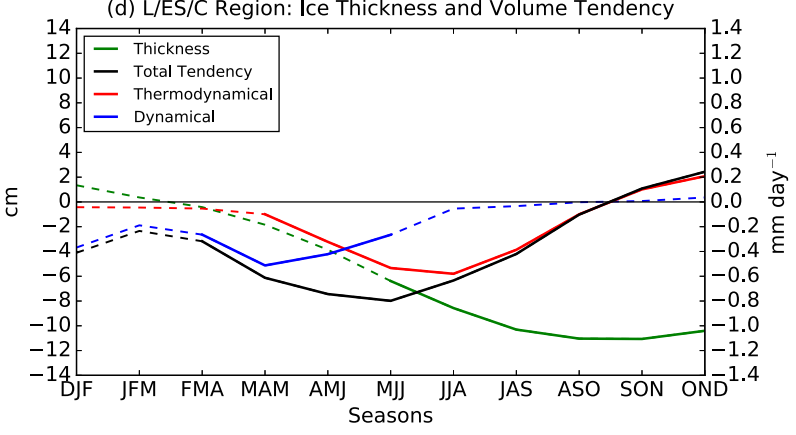

FIG. 6. Time series of running seasonal means of the difference in area-averaged anomalies for (left) the BA region and (right) the L/ES/C region between SPV and SSW years. (top) Sea ice concentration (green) and concentration tendency anomalies (total = black, thermodynamical $=$ red, dynamical $=$ blue). (bottom) Sea ice thickness (green) and volume tendency anomalies (total = black, thermodynamical $=$ red, dynamical $=$ blue). Seasons when the difference between SSWs and SPVs is statistically significant at the $95 \%$ level using a Student's $t$ test are shown with solid lines.

respectively. The model shows significant thickness anomalies in the Beaufort Sea, although there are no significant SIC anomalies in that region. Positive anomalies are likely indicative of thicker multiyear ice advection by the Beaufort Gyre into the Beaufort Sea associated with the positive phase of the AO. We also see only small magnitude thickness anomalies in the BA the $\mathrm{B} / \mathrm{O}$ regions where the sea ice is climatologically thin. Fig. S7 is identical to Fig. 5 except that the thickness anomalies are shown as a percentage of the climatological standard deviation. In this figure, the size of the thickness anomalies with respect to interannual variability is more readily seen, with the anomalies in the BA region being up to $30 \%-40 \%$ of a standard deviation.

In AMJ, we begin to see small anomalies in thickness emerge along the Eurasian coastline and in the Chukchi Sea. By JAS, we see significant thickness anomalies in the L/ES/C region for the SSW and SPV composites, respectively (Figs. 5c and 5f). Positive thickness anomalies are a proxy for coastal sea ice convergence and delayed ice retreat, while negative thickness anomalies are a proxy for divergence and earlier ice retreat. These thickness anomalies are collocated with the JAS SIC anomalies shown in Fig. 4, suggesting that the thickness anomalies contribute to the SIC anomalies by either delaying (SSWs) or accelerating (SPVs) summer ice retreat. Area averaged over the L/ES/C region, the thickness anomalies are approximately $16 \%$ of a standard deviation for SSWs and $32 \%$ for SPVs (see Fig. S7).

We now explore the time-dependent development of the SIC and thickness anomalies in more detail for the two regions of interest: the BA and the L/ES/C regions. Specifically, we will examine the dynamical and thermodynamical contributions to the SIC and thickness tendency anomalies (see, e.g., Landrum et al. 2012; Hunke and Lipscomb 2008; Thorndike et al. 1975). The sea ice model in WACCM includes a subgrid-scale ice thickness distribution, discretized into five thickness categories, that is governed by the following tendency equation:

$$
\frac{\partial g}{\partial t}=-\frac{\partial(f g)}{\partial h}-\nabla \cdot(g \mathbf{u})+\Psi,
$$

where $\mathbf{u}$ is the horizontal ice velocity, $f$ is the rate of thermodynamic ice growth, $\Psi$ is a ridging and rafting redistribution function, and $g$ is the ice thickness distribution. The term $g(h) d h$ is defined as the fractional area covered by ice in the thickness range $h$ to $h+d h$ at a given time and grid cell. The thermodynamic tendency, the first term in Eq. (1), includes basal, surface, and lateral growth and melt processes, while the dynamical 
(a) BA Region: SIC for 5 Thickness Categories

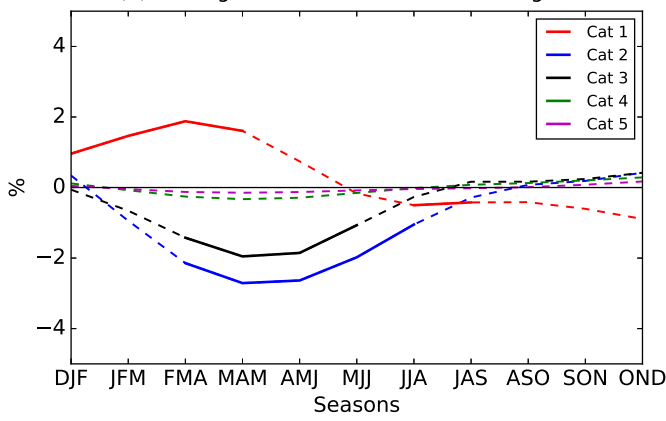

(c) BA Region: Ice Volume for 5 Thickness Categories

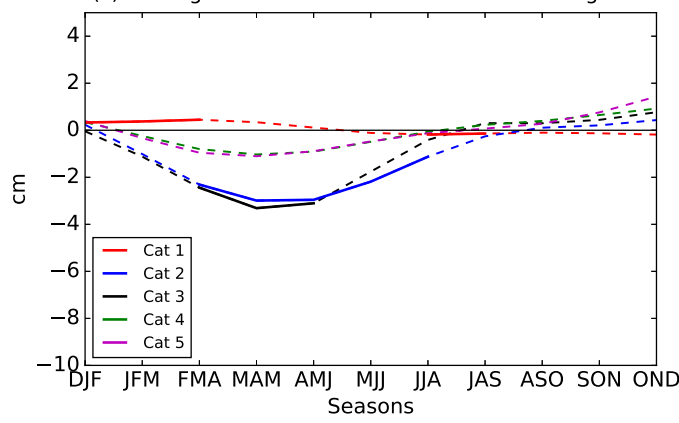

(b) L/ES/C Region: SIC for 5 Thickness Categories
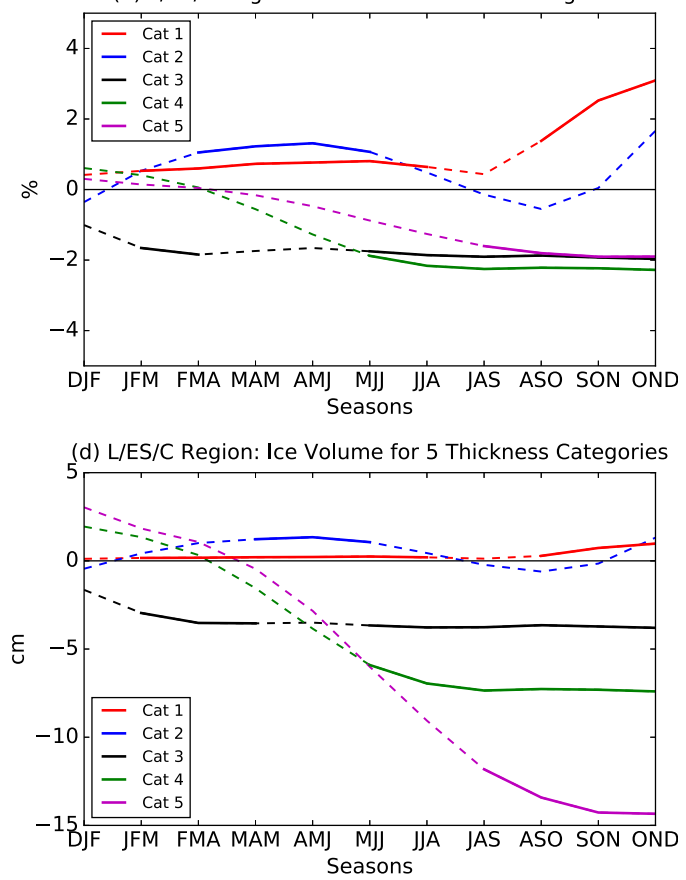

FIG. 7. Time series of running seasonal means of the difference in area-averaged anomalies for (left) the BA region and (right) the L/ES/C region between SPV and SSW years. (top) Sea ice concentration anomalies for five different ice thickness categories. (bottom) Sea ice volume anomalies for the same five ice thickness categories. The lower bounds of the five ice thickness categories are defined as follows: category $1=0.00 \mathrm{~m}$, category $2=0.64 \mathrm{~m}$, category $3=1.39 \mathrm{~m}$, category $4=2.47 \mathrm{~m}$, and category $5=4.57 \mathrm{~m}$. Seasons when the difference between SSWs and SPVs is statistically significant at the 95\% level using a Student's $t$ test are shown with solid lines.

tendency, the last two terms in Eq. (1), includes advective and mechanical redistribution processes. The volume tendency for each ice thickness category is simply the fractional area multiplied by the thickness.

To condense our findings, in Fig. 6, we now show only the difference between SPV and SSW years. Figures 6a and $6 \mathrm{~b}$ show the area-averaged seasonal time series of SIC (green curve) and SIC tendency (black, red, and blue curves) anomalies-the difference between SPV and SSW years-for the BA and L/ES/C regions, respectively. As inferred from Fig. 4, Figs. 6a and 6b show that the BA SIC anomalies reach a minimum in spring and the L/ES/C SIC anomalies reach a minimum in summer.

The SIC tendency anomalies illustrate the processes responsible for the development of SIC anomalies. In the BA region (Fig. 6a), we find that the total SIC tendency anomaly (black curve) consists almost entirely of the dynamical component in winter and spring (blue curve), indicating that ice advection is the primary process. In the $\mathrm{L} / \mathrm{ES} / \mathrm{C}$ region (Fig. $6 \mathrm{~b}$ ), in contrast, we find that a negative dynamical tendency anomaly is offset by a positive thermodynamic tendency anomaly in winter, but that it is the thermodynamical component in spring and summer that contributes to the summer minimum.

Figures $7 \mathrm{a}$ and $7 \mathrm{~b}$ show the seasonal evolution of the SIC anomaly - the difference between SPV and SSW years, as in Fig. 6-for the five sea ice thickness categories. Ice advection in the BA region leads to thin ice growth (category 1), but this is offset by retreat of thicker ice (categories 2 and 3). Because the thermodynamic SIC tendency is roughly zero until late spring (Fig. 6a), some of the loss of the thicker ice is likely due to melt associated with atmospheric or ocean heat transport, as well as advection.

In the $\mathrm{L} / \mathrm{ES} / \mathrm{C}$ region, ice advection in winter leads to growth of ice in categories 1 and 2 and retreat of ice in category 3 (Fig. 7b). This is reflected in the approximate balance between the dynamic and thermodynamic SIC tendencies in Fig. 6b. Later in the season, retreat in the thicker ice categories (categories 4 and 5), associated with thermodynamic processes (Fig. 6b) begin to dominate.

Turning to the volume tendency anomalies in Figs. $6 \mathrm{c}$ and $6 \mathrm{~d}$, we also see differences between the two regions of interest. Although the dynamical volume tendency anomalies in winter are the largest contributor to the total in both regions, the thermodynamical volume tendency anomalies are quite different. In the BA 
(a) SSW Years: JFM

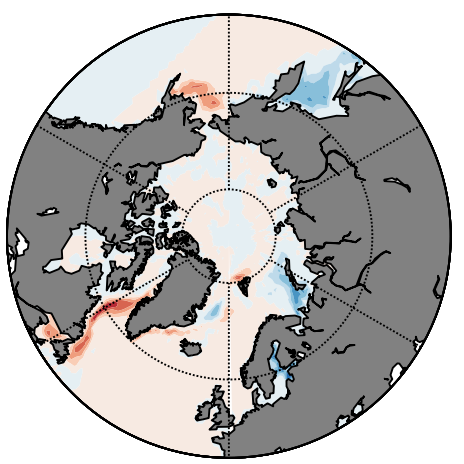

(d) SPV Years: JFM

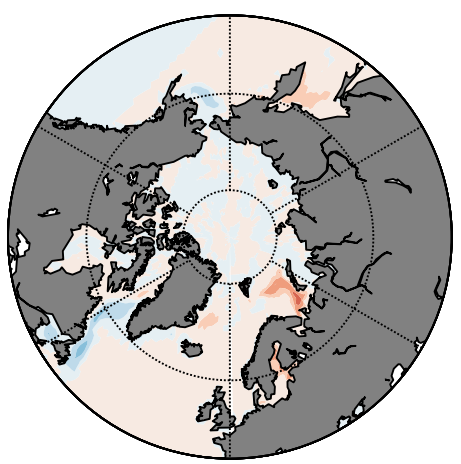

(b) SSW Years: AMJ

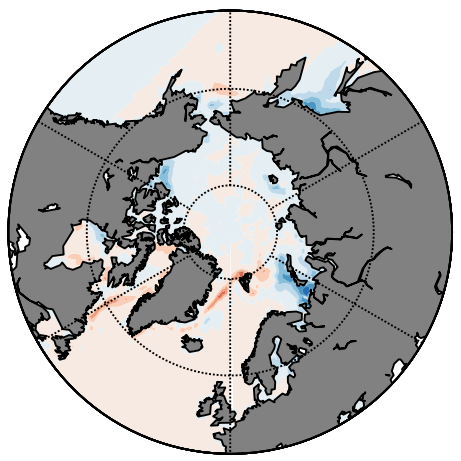

(e) SPV Years: AMJ

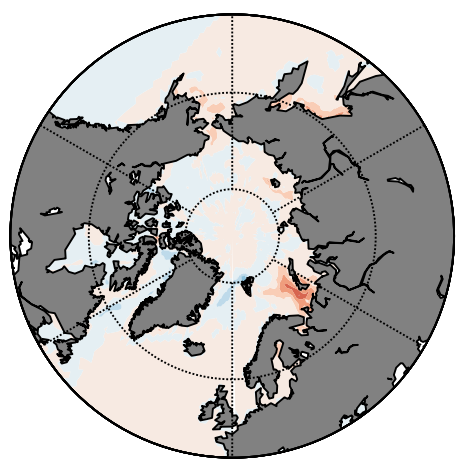

(c) SSW Years: JAS

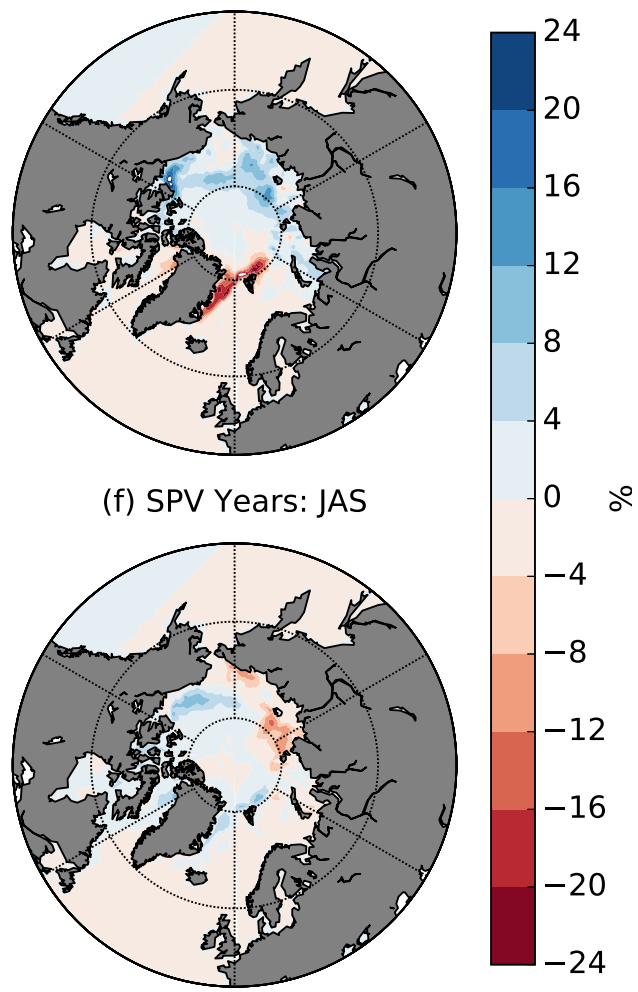

FIG. 8. As in Fig. 4, but for ERA-Interim and NSIDC bootstrap sea ice concentration for 1979-2015. Seasonal means are shown for (a),(d) JFM; (b),(e) AMJ; and (c),(f) JAS.

region, the thermodynamical tendency anomaly occurs essentially at the same time as the dynamical component. In spring, the thermodynamical tendency anomaly dominates because of the slower response of ocean heat flux to the NAO, relative to ice advection (Arthun et al. 2012). However, this thermodynamical component does not appear to contribute to the mean anomalous SIC minimum in spring (see Fig. 6a), but rather to a redistribution of ice thickness in the BA region (Fig. 7a; Thorndike et al. 1975).

In the $\mathrm{L} / \mathrm{ES} / \mathrm{C}$ region, unlike the $\mathrm{BA}$ region, where the volume tendency components tend to covary in time, we see a delay of several months between the minimum in the dynamical and thermodynamical tendency components. We find that the dynamically driven negative anomalies in ice volume in winter and spring are not immediately accompanied by thermodynamically driven negative anomalies. The sumertime thermodynamically driven anomalies in ice volume are preceded by gradual dynamical thinning of the ice. The delay may be related to the fact that the ice in this region is climatologically thicker and, thus, it takes several months for the ice to get thin enough to promote strong feedbacks between ice thickness and ice melt, which then leads to early onset of spring/summer retreat.
As above, we show the seasonal evolution of the sea ice volume anomaly - the difference between SPV and SSW years-for five sea ice thickness categories (Figs. 7c and $7 \mathrm{~d}$ ). In both regions, we see complementary categorical contributions to the ice volume anomalies as was shown above for the SIC anomalies (Figs. 7a and 7b). Further examination of the ice-atmosphere-ocean energy budget is ongoing in order to attribute these anomalies to specific atmospheric and oceanic processes.

\section{Observational evidence of a stratospheric impact on Arctic sea ice}

Based on model output, we have built a case for the existence of significant Arctic sea ice anomalies following stratospheric circulation extremes. Using a long WACCM time-slice integration has allowed us to separate SSW and SPV events while maintaining large composite sizes, thus, robust statistics. We now turn to the observational Arctic sea ice extent record, where the analysis is complicated by large, nonlinear trends and a relatively short time series. Despite these issues, we now show that similar SIC anomalies associated with SSW and SPV events can be seen in the observations. 

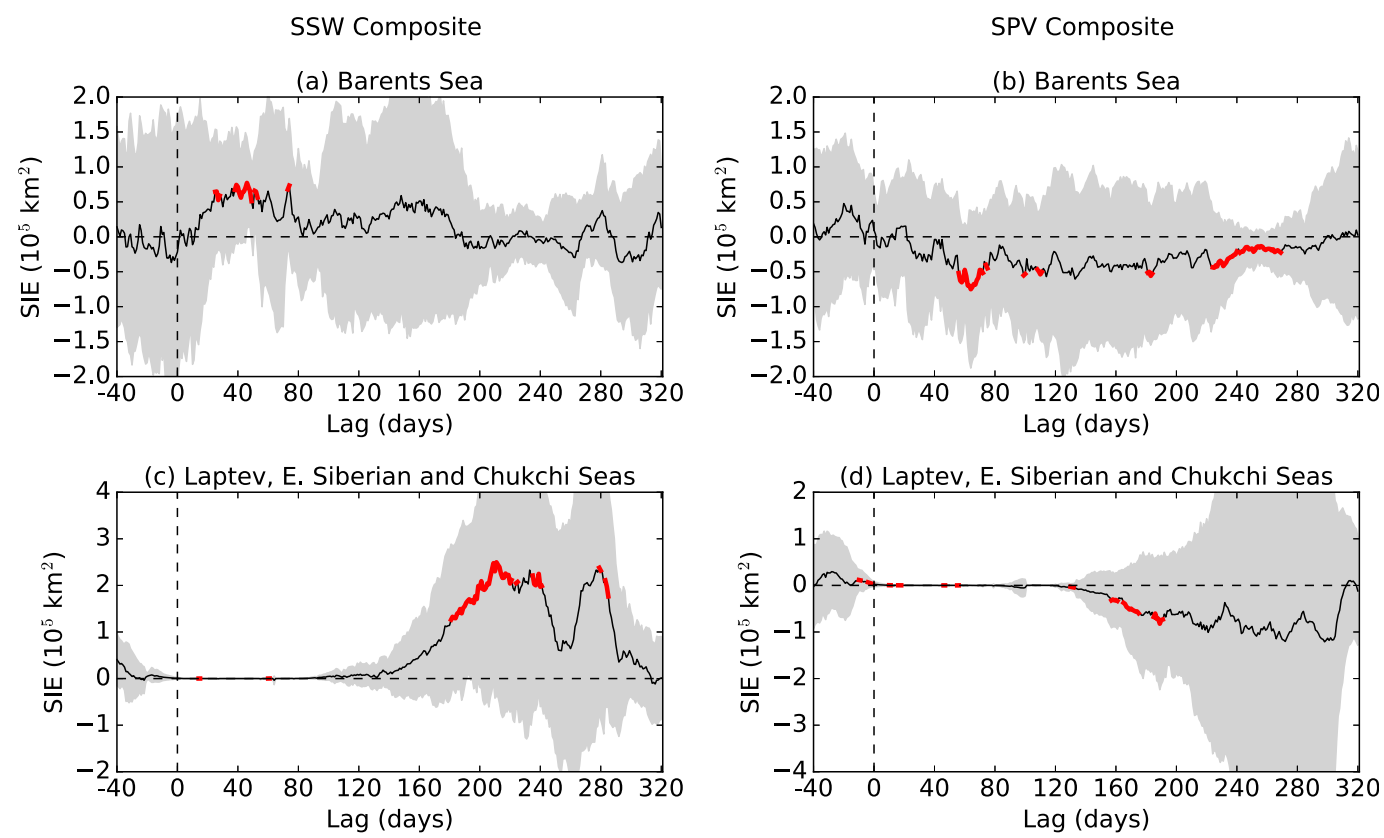

FIG. 9. Composite mean SIE anomaly time series as a function of lag (days) for (left) SSWs and (right) SPVs using ERA-Interim and NSIDC bootstrap sea ice concentration for 1979-2015. (a),(b) Barents Sea $\left(70^{\circ}-80^{\circ} \mathrm{N}, 20^{\circ}-60^{\circ} \mathrm{E}\right)$; and (c),(d) Laptev, East Siberian, and Chukchi Seas $\left(65^{\circ}-80^{\circ} \mathrm{N}, 92^{\circ}-200^{\circ} \mathrm{E}\right)$. Composites consist of 8 SSWs and 14 SPVs. Days that are statistically significant at the $90 \%$ level using a Student's $t$ test are indicated by the solid red line. Gray shading shows \pm 1 standard deviation across the SSW and SPV events. The black vertical line at day zero indicates the central date of the SSW and SPV events.

As stated above, in the ERA-Interim reanalysis data, only 8 SSW and 14 SPV nonoverlapping winters are found since 1979. In Fig. 8 we show the seasonal composite mean SIC for SSW (top row) and SPV (bottom row) events. Figure 8 can be compared to Fig. 4 (but note the different color bar range). The observations show a similar pattern of SIC anomalies in the Sea of Okhotsk in JFM, the BA region in JFM and AMJ, and the $\mathrm{L} / \mathrm{ES} / \mathrm{C}$ region in JAS. Given the small number of events in the composites, statistical significance in Fig. 8 is very noisy and not shown; however, Fig. 9 shows composite time series of SIE for the BA and L/ES/C regions following SSW and SPV events with statistical significance indicated (cf. WACCM in Fig. 3). We see that the SIE anomalies in these regions are statistically significant (at the $90 \%$ level), despite the small composite sizes, and that the timing of the anomalies following SSW and SPV events agrees well with the model. As in WACCM, we did not find significant anomalies in panArctic September SIE following stratospheric circulation extremes in the observational record (not shown).

\section{Conclusions}

In this study, we have demonstrated a clear relationship between stratospheric circulation extremes, namely, stratospheric sudden warmings (SSWs) and strong polar vortex events (SPVs), and Arctic sea ice anomalies in the following months, using a long timeslice model integration. Composite analysis of SSWs and SPVs reveals significant and opposite-signed regional SIE anomalies: these are found in the Bering Strait and Sea of Ohkotsk (B/O) in winter, the Barents Sea (BA) in spring, and the Laptev, East Siberian, and Chukchi Seas $(\mathrm{L} / \mathrm{ES} / \mathrm{C})$ in summer.

In the BA region, we show that SIE anomalies are primarily driven by winter ice advection (Fig. 6), whereas SIE anomalies in the $\mathrm{L} / \mathrm{ES} / \mathrm{C}$ region are associated with sea ice thickness anomalies, initially generated by coastal sea ice divergence in late winter and subsequently enhanced by thermodynamical feedbacks in spring and summer. These findings agree with many studies (Rigor et al. 2002; Rigor and Wallace 2004; Strong et al. 2009; Ogi et al. 2010; Wu and Zhang 2010; Stroeve et al. 2011; Wettstein and Deser 2014; Williams et al. 2016; Itkin and Krumpen 2017) that have demonstrated the link between the AO/NAO, sea ice divergence, and Arctic sea ice concentration anomalies. Here, we extend this link back to the stratosphere.

We have also shown, albeit with rather limited samples, that similar SIC patterns following SSW and SPV events exist in the observational record, particularly in 
the BA region, where the model and the observations are in good agreement. This gives us confidence that our analysis derived from the model has identified a potentially important stratospheric source of Arctic sea ice predictability.

One potential source of uncertainty associated with this work is the WACCM climatological sea ice thickness bias, particularly along the Eurasian coast, and whether this bias has an influence on our results. Our preliminary assessment is that this bias likely makes the magnitude of the SIC anomalies that we identify conservative. The wind-driven atmosphere-sea ice coupling is likely weaker in WACCM given that the climatologically thicker sea ice would be less responsive to anomalies in wind forcing. In addition, when there is anomalous coastal sea ice divergence in WACCM, the ice-albedo feedback associated with ice drift away from the coastline would likely be diminished as a result of the presence of climatologically thicker ice. Further research is required to quantify the effect of the climatological sea ice thickness bias on the strength of atmosphere-sea ice coupling in WACCM.

Although we did not find anomalies in pan-Arctic September Arctic sea ice extent following stratospheric circulation extremes in either the model or the observations, we did find significant anomalies in sea ice extent following SSWs and SPVs in the L/ES/C region extending into the fall. Our analysis agrees with the observational study of Williams et al. (2016) that highlighted the significant relationship between the winter $\mathrm{AO}$ and sea ice divergence in this region and September Arctic SIE, suggesting that the presence or absence of stratospheric circulation extremes in winter may play a nontrivial role in determining total September Arctic SIE when combined with other factors.

Finally, we note that since stratospheric anomalies precede $\mathrm{AO}$ anomalies in the troposphere, there is some potential to extend the period over which skillful prediction of Arctic SIE may be achieved if knowledge of stratospheric conditions is known. However, translating stratospheric information into a skillful predictor of SIE presents challenges. The magnitude of stratospheric circulation anomalies is not linearly related to the subsequent, coupled tropospheric anomalieshence the ubiquitous use of composite analysis in the SSW literature (e.g., Scaife et al. 2016). This characteristic likely makes stratospheric circulation anomalies a poor predictor of Arctic SIE in a linear statistical modeling framework. Including stratospheric information as a binary predictor (i.e., the presence or absence of SSWs and SPVs) may be a more fruitful approach, an avenue of research that we plan to pursue.
Acknowledgments. KLS, LMP, and LBT are supported by the National Science Foundation Office of Polar Programs, Arctic Research Opportunities, PLR1603350. LBT is also supported by the Office of Naval Research, N000141110977. Model output is archived on the High Performance Storage System (HPSS) maintained by the National Center for Atmospheric Research's (NCAR) Computational and Information Systems Lab (CISL). All model output is available upon request.

\section{REFERENCES}

Arthun, M., T. Eldevik, L. H. Smedsrud, O. Skagseth, and R. B. Ingvaldsen, 2012: Quantifying the influence of Atlantic heat on Barents sea ice variability and retreat. J. Climate, 25, 47364743, https://doi.org/10.1175/JCLI-D-11-00466.1.

Baldwin, M., and T. Dunkerton, 2001: Stratospheric harbingers of anomalous weather regimes. Science, 294, 581-584, https:// doi.org/10.1126/science.1063315.

Bitz, C. M., M. M. Holland, E. C. Hunke, and R. E. Moritz, 2005: Maintenance of the sea-ice edge. J. Climate, 18, 2903-2921, https://doi.org/10.1175/JCLI3428.1.

Bushuk, M., R. Msadek, M. Winton, G. A. Vecchi, R. Gudgel, A. Rosati, and X. Yang, 2017: Skillful regional prediction of Arctic sea ice on seasonal timescales. Geophys. Res. Lett., 44, 4953-4964, https://doi.org/10.1002/2017GL073155.

Butler, A. H., D. J. Seidel, S. C. Hardiman, N. Butchart, T. Birner, and A. Match, 2015: Defining sudden stratospheric warmings. Bull. Amer. Meteor. Soc., 96, 1913-1928, https://doi.org/ 10.1175/BAMS-D-13-00173.1.

Cai, D., M. Dameris, H. Garny, and T. Runde, 2012: Implications of all season Arctic sea-ice anomalies on the stratosphere. Atmos. Chem. Phys., 12, 11 819-11 831, https://doi.org/10.5194/ acp-12-11819-2012.

Charlton-Perez, A. J., and L. Polvani, 2007: A new look at stratospheric sudden warmings. Part I: Climatology and modeling benchmarks. J. Climate, 20, 449-469, https://doi.org/10.1175/ JCLI3996.1.

, and Coauthors, 2013: On the lack of stratospheric dynamical variability in low-top versions of the CMIP5 models. J. Geophys. Res. Atmos., 118, 2494-2505, https://doi.org/ 10.1002/jgrd.50125.

Chen, Z., J. Liu, M. Song, Q. Yang, and S. Xu, 2017: Impacts of assimilating satellite sea ice concentration and thickness on Arctic sea ice prediction in the NCEP Climate Forecast System. J. Climate, 30, 8429-8446, https://doi.org/10.1175/ JCLI-D-17-0093.1.

Chevallier, M., and D. Salas-Mélia, 2012: The role of sea ice thickness distribution in the Arctic sea ice potential predictability: A diagnostic approach with a coupled GCM. J. Climate, 25, 3025-3038, https://doi.org/10.1175/ JCLI-D-11-00209.1.

Comiso, J., 2000: Bootstrap sea ice concentrations from Nimbus-7 SMMR and DMSP SSM/I-SSMIS, version 2. National Snow and Ice Data Center Distributed Active Archive Center. Subset used: Northern Hemisphere daily data (updated yearly), accessed 9 September 2016, https://doi.org/ 10.5067/J6JQLS9EJ5HU.

Dee, D. P., and Coauthors, 2011: The ERA-Interim reanalysis: Configuration and performance of the data assimilation 
system. Quart. J. Roy. Meteor. Soc., 137, 553-597, https://doi.org/ $10.1002 /$ qj. 828 .

Douville, H., 2009: Stratospheric polar vortex influence on Northern Hemisphere winter climate variability. Geophys. Res. Lett., 36, L18703, https://doi.org/10.1029/2009GL039334.

Feldstein, S. B., and S. Lee, 2014: Intraseasonal and interdecadal jet shifts in the Northern Hemisphere: The role of warm pool tropical convection and sea ice. J. Climate, 27, 6497-6518, https://doi.org/10.1175/JCLI-D-14-00057.1.

Garfinkel, C. I., A. H. Butler, D. W. Waugh, M. M. Hurwitz, and L. M. Polvani, 2012: Why might stratospheric sudden warmings occur with similar frequency in El Niño and La Niña winters? J. Geophys. Res., 117, D19106, https://doi.org/ 10.1029/2012JD017777.

Holland, M. M., and J. Stroeve, 2011: Changing seasonal sea ice predictor relationships in a changing Arctic climate. Geophys. Res. Lett., 38, L18501, https://doi.org/10.1029/2011GL049303.

Hunke, E. C., and W. H. Lipscomb, 2008: CICE: The Los Alamos sea ice model, documentation and software, version 4.0. Los Alamos National Laboratory Tech. Rep. LA-CC-06-012, 76 pp.

Itkin, P., and T. Krumpen, 2017: Winter sea ice export from the Laptev Sea preconditions the local summer sea ice cover and fast ice decay. Cryosphere, 11, 2383-2391, https://doi.org/ 10.5194/tc-11-2383-2017.

Jung, T., and Coauthors, 2016: Advancing polar prediction capabilities on daily to seasonal time scales. Bull. Amer. Meteor. Soc., 97, 1631-1647, https://doi.org/10.1175/ BAMS-D-14-00246.1.

Kim, B.-M., S.-W. Son, S.-K. Min, J.-H. Jeong, S.-J. Kim, X. Zhang, T. Shim, and J.-H. Yoon, 2014: Weakening of the stratospheric polar vortex by Arctic sea-ice loss. Nat. Commun., 5, 4646, https://doi.org/10.1038/ncomms5646.

Kimura, N., A. Nishimura, Y. Tanaka, and H. Yamaguchi, 2013: Influence of winter sea-ice motion on summer ice cover in the Arctic. Polar Res., 32, 20193, https://doi.org/10.3402/ polar.v32i0.20193.

Koenigk, T., U. Mikolajewicz, J. H. Jungclaus, and A. Kroll, 2009: Sea ice in the Barents Sea: Seasonal to interannual variability and climate feedbacks in a global coupled model. Climate Dyn., 32, 1119-1138, https://doi.org/10.1007/ s00382-008-0450-2.

Landrum, L., M. M. Holland, D. P. Schneider, and E. Hunke, 2012: Antarctic sea ice climatology, variability, and late twentiethcentury change in CCSM4. J. Climate, 25, 4817-4838, https:// doi.org/10.1175/JCLI-D-11-00289.1.

Marsh, D. R., M. J. Mills, D. E. Kinnison, J.-F. Lamarque, N. Calvo, and L. M. Polvani, 2013: Climate change from 1850 to 2005 simulated in CESM1(WACCM). J. Climate, 26, 73727391, https://doi.org/10.1175/JCLI-D-12-00558.1.

Ogi, M., K. Yamazaki, and J. M. Wallace, 2010: Influence of winter and summer surface wind anomalies on summer Arctic sea ice extent. Geophys. Res. Lett., 37, L07701, https://doi.org/ 10.1029/2009GL042356.

Peings, Y., and G. Magnusdottir, 2014: Response of the wintertime Northern Hemisphere atmospheric circulation to current and projected Arctic sea ice decline: A numerical study with CAM5. J. Climate, 27, 244-264, https://doi.org/10.1175/ JCLI-D-13-00272.1.

Petty, A. A., D. Schroder, J. C. Stroeve, T. Markus, J. Miller, N. T. Kurtz, D. L. Feltman, and D. Flocco, 2017: Skillful spring forecasts of September Arctic sea ice extent using passive microwave sea ice observations. Earth's Future, 5, 254-263, https://doi.org/10.1002/2016EF000495.
Polvani, L. M., L. Sun, A. H. Butler, J. H. Richter, and C. Deser, 2017: Distinguishing stratospheric sudden warmings from ENSO as key drivers of wintertime climate variability over the North Atlantic and Eurasia. J. Climate, 30, 1959-1969, https:// doi.org/10.1175/JCLI-D-16-0277.1.

Rigor, I. G., and J. M. Wallace, 2004: Variations in the age of Arctic sea-ice and summer sea-ice extent. Geophys. Res. Lett., 31, L09401, https://doi.org/10.1029/2004GL019492.

_ _ _ and R. L. Colony, 2002: Response of sea ice to the Arctic Oscillation. J. Climate, 15, 2648-2663, https://doi.org/ 10.1175/1520-0442(2002)015<2648:ROSITT >2.0.CO;2.

Scaife, A. A., J. R. Knight, G. K. Vallis, and C. K. Folland, 2005: A stratospheric influence on the winter NAO and North Atlantic surface climate. Geophys. Res. Lett., 32, L18715, https://doi.org/ 10.1029/2005GL023226.

— , and Coauthors, 2016: Seasonal winter forecasts and the stratosphere. Atmos. Sci. Lett., 17, 51-56, https://doi.org/ 10.1002/asl.598.

Schröder, D., D. L. Feltham, D. Flocco, and M. Tsamados, 2014: September Arctic sea-ice minimum predicted by spring meltpond fraction. Nat. Climate Change, 4, 353-357, https://doi.org/ 10.1038/nclimate2203.

Scinocca, J. F., M. C. Reader, D. A. Plummer, M. Sigmond, P. J. Kushner, T. G. Shepherd, and R. Ravishankara, 2009: Impact of sudden Arctic sea-ice loss on stratospheric polar ozone recovery. Geophys. Res. Lett., 36, L24701, https:// doi.org/10.1029/2009GL041239.

Shu, Q., Z. Song, and F. Qiao, 2015: Assessment of sea ice simulations in the CMIP5 models. Cryosphere, 9, 399-409, https:// doi.org/10.5194/tc-9-399-2015.

Sigmond, M., J. F. Scinocca, V. V. Kharin, and T. G. Shepherd, 2013: Enhanced seasonal forecast skill following stratospheric sudden warmings. Nat. Geosci., 6, 98-102, https://doi.org/ 10.1038/ngeo1698.

Sorteberg, A., and B. Kvingedal, 2006: Atmospheric forcing on the Barents Sea winter ice extent. J. Climate, 19, 4772-4784, https://doi.org/10.1175/JCLI3885.1.

Stroeve, J. C., J. Maslanik, M. C. Serreze, I. Rigor, W. Meier, and C. Fowler, 2011: Sea ice response to an extreme negative phase of the Arctic Oscillation during winter 2009/2010. Geophys. Res. Lett., 38, L02502, https://doi.org/10.1029/ 2010 GL045662.

— V. Kattsov, A. Barrett, M. Serreze, T. Pavlova, M. Holland, and W. N. Meier, 2012: Trends in Arctic sea ice extent from CMIP5, CMIP3 and observations. Geophys. Res. Lett., 39, L16502, https://doi.org/10.1029/2012GL052676.

— A. Barrett, M. Serreze, and A. Schweiger, 2014a: Using records from submarine, aircraft and satellites to evaluate climate model simulations of Arctic sea ice thickness. Cryosphere, 8, 1839-1854, https://doi.org/10.5194/tc-8-18392014.

_ L. C. Hamilton, C. M. Bitz, and E. Blanchard-Wrigglesworth, 2014b: Predicting September sea ice: Ensemble skill of the SEARCH Sea Ice Outlook 2008-2013. Geophys. Res. Lett., 41, 2411-2418, https://doi.org/10.1002/2014GL059388.

—, E. Blanchard-Wrigglesworth, V. Guemas, S. Howell, F. Massonnet, and S. Tietsche, 2015: Improving predictions of Arctic sea ice extent. Eos, Earth and Space Science News, No. 96, 10-15, https://doi.org/10.1029/2015EO031431.

Strong, C., and G. Magnusdottir, 2010: Modeled winter sea ice variability and the North Atlantic Oscillation: A multi-century perspective. Climate Dyn., 34, 515-525, https://doi.org/10.1007/ s00382-009-0550-7. 
and K. M. Golden, 2016: Filling the polar data gap in sea ice concentration fields using partial differential equations. Remote Sens., 8, 442, https://doi.org/10.3390/rs8060442.

, G. Magnusdottir, and H. Stern, 2009: Observed feedback between winter sea ice and the North Atlantic Oscillation. J. Climate, 22, 6021-6032, https://doi.org/10.1175/ 2009JCLI3100.1.

Sun, L., C. Deser, L. Polvani, and R. Tomas, 2014: Influence of projected Arctic sea ice loss on polar stratospheric ozone and circulation in spring. Environ. Res. Lett., 9, 084016, https:// doi.org/10.1088/1748-9326/9/8/084016.

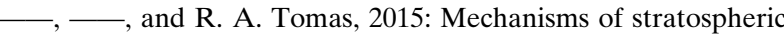
and tropospheric circulation response to projected Arctic sea ice loss. J. Climate, 28, 7824-7845, https://doi.org/10.1175/ JCLI-D-15-0169.1.

Thorndike, A. S., D. A. Rothrock, G. A. Maykut, and R. Colony, 1975: The thickness distribution of sea ice. J. Geophys. Res. 80, 4501-4513, https://doi.org/10.1029/JC080i033p04501.

Tietsche, S., D. Notz, J. H. Jungclaus, and J. Marotzke, 2013: Predictability of large interannual Arctic sea-ice anomalies. Climate Dyn., 41, 2511-2526, https://doi.org/10.1007/s00382-013-1698-8.

Wettstein, J. J., and C. Deser, 2014: Internal variability in projections of twenty-first-century Arctic sea ice loss: Role of the large-scale atmospheric circulation. J. Climate, 27, 527-550, https://doi.org/10.1175/JCLI-D-12-00839.1.
Williams, J., B. Tremblay, R. Newton, and R. Allard, 2016: Dynamic preconditioning of the minimum September sea-ice extent. J. Climate, 29, 5879-5891, https://doi.org/10.1175/ JCLI-D-15-0515.1.

$\mathrm{Wu}, \mathrm{Q}$., and X. Zhang, 2010: Observed forcing feedback processes between Northern Hemisphere atmospheric circulation and Arctic sea ice coverage. Geophys. Res. Lett., 115, D14119, https://doi.org/10.1029/2009JD013574.

Wu, Y., and K. L. Smith, 2016: Response of Northern Hemisphere midlatitude circulation to Arctic amplification in a simple atmospheric general circulation model. J. Climate, 29, 20412058, https://doi.org/10.1175/JCLI-D-15-0602.1.

Yang, X. Y., X. Yuan, and M. Ting, 2016: Dynamical link between the Barents-Kara Sea ice and the Arctic Oscillation. J. Climate, 29, 5103-5122, https://doi.org/10.1175/JCLI-D-15-0669.1.

Zhang, J., and D. A. Rothrock, 2003: Modeling global sea ice with a thickness and enthalpy distribution model in generalized curvilinear coordinates. Mon. Wea. Rev., 131, 845-861, https://doi.org/10.1175/1520-0493(2003)131<0845: MGSIWA $>2.0 . \mathrm{CO} ; 2$.

Zhang, P., Y. Wu, and K. Smith, 2018: Prolonged effect of the stratospheric pathway in linking Barents-Kara Sea sea ice variability to the midlatitude circulation in a simplified model. Climate Dyn., 50, 527-539, https://doi.org/10.1007/ s00382-017-3624-y. 